\title{
Centromere B Antibody Measurement
}

National Cancer Institute

\section{Source}

National Cancer Institute. Centromere B Antibody Measurement. NCI Thesaurus. Code C111154.

A measurement of centromere B antibodies present in a sample. 